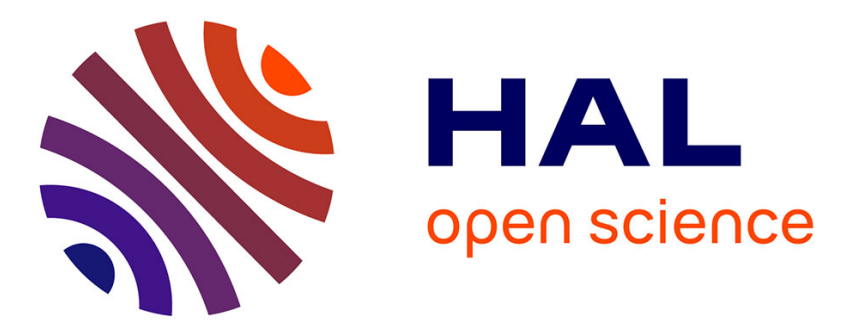

\title{
On Improving the Formability of AA6061/SiCp Composite Synthesized Using Friction Stir Processing
}

M Puviyarasan, V S Senthil Kumar, D Viswanathan, K A Padmanabhan

\section{To cite this version:}

M Puviyarasan, V S Senthil Kumar, D Viswanathan, K A Padmanabhan. On Improving the Formability of AA6061/SiCp Composite Synthesized Using Friction Stir Processing. EuroSPF 2016, Institut Clement Ader and Ecole des Mines d'Albi, Sep 2016, TOULOUSE, France. hal-01363688v2

\section{HAL Id: hal-01363688 \\ https://hal.science/hal-01363688v2}

Submitted on 19 Sep 2016

HAL is a multi-disciplinary open access archive for the deposit and dissemination of scientific research documents, whether they are published or not. The documents may come from teaching and research institutions in France or abroad, or from public or private research centers.
L'archive ouverte pluridisciplinaire HAL, est destinée au dépôt et à la diffusion de documents scientifiques de niveau recherche, publiés ou non, émanant des établissements d'enseignement et de recherche français ou étrangers, des laboratoires publics ou privés. 


\title{
ON IMPROVING THE FORMABILITY OF AA6061/SiC COMPOSITE SYNTHESIZED Using Friction Stir Processing
}

\author{
M. Puviyarasan ${ }^{1}$, V. S. Senthil Kumar ${ }^{2}$, D. Viswanathan ${ }^{3}$ \& K. A. Padmanabhan ${ }^{4}$ \\ ${ }^{1}$ Research Scholar, Department of Mechanical Engineering, Anna University, Chennai - 600 025, India \\ muthupuvi@gmail.com \\ ${ }^{2}$ Associate Professor, Department of Mechanical Engineering, Anna University, Chennai - 600 025, India \\ vssk70@gmail.com \\ ${ }^{3}$ Professor (Retd.), Department of Mechanical Engineering, Anna University, Chennai - 600 025, India \\ doraiviswa@gmail.com \\ ${ }^{4}$ Professor of Eminence, Department of Mechanical Engineering, Anna University, Chennai - 600025 , India \\ ananthaster@gmail.com
}

\begin{abstract}
Friction stir processing (FSP) is a potentially useful method for producing composites of enhanced surface properties. In this work, an AA6061/SiC $\mathrm{p}_{\mathrm{p}}$ composite, synthesized using FSP, was tested in three-point bending and uni-axial hot tensile and bi-axial stressing to assess its formability. Bending test results reveal an increased bending strength in the composite compared with the AA 6061 alloy, subjected to FSP, but without the addition of the SiC particles. Based on the hot tensile tests, the biaxial stressing temperatures were fixed as $623 \mathrm{~K}$ and $673 \mathrm{~K}$. Bi-axial stressing reveals that a maximum bulge height of $18 \mathrm{~mm}$ could be obtained by forming into a cavity of $59 \mathrm{~mm}$ diameter at a pressure of $0.2 \mathrm{MPa}$. Based on the results, process parameters such as formed bulge height, forming time, strain rate and strain rate sensitivity index were determined. In the present experiments, the strain rate sensitivity index increased with increasing forming pressure and reached a maximum value of 0.40 at a forming pressure of 0.25 , as the latter variable was increased from 0.20 to $0.25 \mathrm{MPa}$. Microstructures and forming limit diagram of the composite were obtained and analysed in detail. The present findings can pave the way for the commercial exploitation of FSP-technology-based, efficient processing of the $\mathrm{AA} \mathrm{k} 061 / \mathrm{SiC} \mathrm{p}_{\mathrm{p}}$ composite.
\end{abstract}

Keywords:

Friction stir processing; Formability; Three-point bending test; Forming limit diagram.

\section{INTRODUCTION}

Research in manufacturing engineering is currently focussed on the development of new fuelefficient, light-weight, high-performance engineering materials. Aluminium-based metal matrix composites are among the materials that play a pivotal role in aerospace, automotive, nuclear, military and marine applications owing to their light weight, high specific stiffness, high formability, and improved wear resistance. Yet, these composites are often brittle due to the addition of reinforcements which also affect their surface properties and reduce service life. Therefore, it is imperative to fabricate composites of superior strength and adequate ductility.

Friction stir processing (FSP), a novel solid state processing technique, has gained acceptance as a potential method for fabricating composites of enhanced surface properties. The process locally refines microstructure, reduces defects, and improves formability. It also eliminates the porosity due to hydrogen present in aluminium composites, which is introduced during casting. Defects such as non-uniform solute redistribution, solidification and liquation cracking and interfacial reaction between the matrix and the reinforcing particles present in aluminium composites are also eliminated. Moreover, FSP is unique in that localized composites can be produced, whereas other techniques can only give rise to bulk composites. This may not be economical in many 
applications. During FSP, initially, a groove is cut on the surface to pack it with the reinforcing particles. Later a pin-less FSP-like tool is used to cover the top of the grooves to prevent the loss / scattering of the particles during fabrication. Finally, an FSP tool with a pin is inserted and traversed through the entire length of the work-piece to produce the composite.

In composites properly produced by FSP, the inner matrix retains its ductility and toughness while the outer surface has better wear resistance and strength. Fine grains that are inherent in the stirred region of composites could facilitate superplasticity. The reinforcements commonly used in aluminium matrix composites are silicon carbide particles. These composites are widely used, e.g. as structural composites. Mahoney and Lynch (2000), Charit and Mishra (2003), and Ma et al. (2004) have suggested friction stir processing as a simple and effective technique for producing microstructures amenable for superplasticity at higher strain rates, lower temperatures and lower flow stresses. Many researchers have established superplasticity in friction stir processed alloys through elevated temperature tensile tests. This possibility has opened up new avenues for research such as selective superplasticity, thicker sheet superplasticity and superplastic forging (Mishra 2004).

Cavaliere and Squillace (2005) have conducted hot tensile tests at different temperatures and strain rates on FSP AA7075 samples. Often, the curves did not display a steady state. Still, they have concluded that at high temperatures a sigmoidal relationship exists between the flow stress and the strain rate. Kannan et al. (1998) have evaluated at $500^{\circ} \mathrm{C}$ and $550^{\circ} \mathrm{C}$ the superplastic properties of a modified 5083 alloy under uniaxial tension. (ASTM dog bone shaped specimens were subjected to deformation at constant cross-head speeds.) The strain rates varied in the range $5 \times 10^{-4} \mathrm{~s}^{-1}$ to $10^{-1} \mathrm{~s}^{-1}$ and the initial grain size lay between 8.7 and $17 \mu \mathrm{m}$. In conformity with well-known results, a finer grain size led to superior superplastic behaviour compared with that of coarse grained variants.

Barnes (2007) has highlighted the significant advances in superplastic forming (SPF) in the areas of alloy development, development of improved forming techniques and new equipment as well as the ever-increasing number of applications in aerospace and automotive markets. Combining FSW (friction stir welding)/ FSP and SPF for creating new and unique product forms and obtaining more economical solutions for light-weight aerospace components has also been discussed. Giuliano (2012) evaluated using bulge forming at $723 \mathrm{~K}$ and constant pressure the displacement and thickness at the pole of a dome of the alloy AA5083. He has stated that the pole of the dome alone experiences equi-biaxial stressing. From the edge to the pole, the nature of the stress is changed. As a result, the thickest location is observed at the periphery of the sheet, with the pole being the thinnest location. A similar result has been obtained by Jung-Ho Cheng (1996).

Karthikeyan et al. (2013) investigated the superplastic forming behaviour of multi-pass FSP AA6063-T6 aluminium alloy at different forming temperatures and pressures by forming a hemispherical component. They could successfully form the FSP samples while the as-received material did not have the needed formability. Therefore, they concluded that FSP is useful in inducing superplasticity in aluminium alloys within an optimal forming temperature and strain rate range (617 K and $10^{-2} \mathrm{~s}^{-1}$ in their study). With FSP A319 cast aluminium alloy, however, full height of the dome could not be formed (Karthikeyan et al. 2010). By superplastically forming the AA7475 aluminium alloy into a hemisphere at different pressures and temperatures, Senthil Kumar et al. (2006) have demonstrated that there is a decrease in the forming time with an increase in the pressure of forming at a constant temperature. With continued forming, the area of the bulge profile increased, while the thickness decreased. The rate of increase in strain rate is more or less uniform in the final stages. 
In this work, FSP is used to reinforce the AA6061 matrix with SiC particles. Using optimal FSP parameters, which would maximize both the ultimate tensile strength and the micro-hardness, the AA6061/SiC $\mathrm{p}_{\mathrm{p}}$ composites were produced. Uni-axial hot tensile tests were performed for determining the temperature of maximum percentage elongation. $623 \mathrm{~K}$ and $673 \mathrm{~K}$ were identified as the optimal temperatures for bi-axial superplastic forming. Variables useful in bulge forming such as forming height, forming time, strain rate and strain rate sensitivity index were determined. In actual bi-axial blow forming experiments, a maximum bulge height of $18 \mathrm{~mm}$ was obtained at $623 \mathrm{~K}$ and a forming pressure of $0.2 \mathrm{MPa}$.

\section{MATERIALS AND METHODS}

\subsection{Materials}

In the present investigation, commercially available AA6061-T6 was selected as the matrix material in the form of a rolled plate of $6 \mathrm{~mm}$ thickness, $140 \mathrm{~mm}$ length and $100 \mathrm{~mm}$ width. The chemical composition determined using an optical emission spectrometer was Al-0.925Mg$0.565 \mathrm{Si}-0.24 \mathrm{Fe}-0.285 \mathrm{Cu}-0.10 \mathrm{Mn}-0.02 \mathrm{Ti}-0.001 \mathrm{Zn}$. Silicon Carbide (SiC) particles with an average size of $6 \mu \mathrm{m}$ were used as reinforcements during the fabrication of the composite.

\subsection{Fabrication of the Composite}

Friction stir processing was carried out using an indigenously designed and developed servocontrolled machine. A hardened $\mathrm{H} 13$ tool with a flat shoulder of $18 \mathrm{~mm}$ diameter and a threaded cylindrical pin of $6 \mathrm{~mm}$ diameter and $4.5 \mathrm{~mm}$ length was used for processing.

For fabricating the composites, using a milling machine a groove with a width of $1.5 \mathrm{~mm}$ and depth of $4 \mathrm{~mm}$ was cut in the specimens. The $\mathrm{SiC}$ particles (reinforcements) were filled in the groove. Later, a pin-less FSP-like tool was employed to cover the top of the groove to prevent the scattering of the particles during fabrication. The next stage was inserting an FSP tool with a pin, till the shoulder head reached below the upper surface of the workpiece and traversing it through the entire length of the work-piece in a direction perpendicular to the rolling direction. The volume fraction of particles is $22.22 \%$ and all the present studies used a single-pass FSP process. The parameters used for fabrication are: tool rotational speed $1221 \mathrm{rpm}$, traverse feed $60 \mathrm{~mm} . \mathrm{min}^{-1}$, tool tilt angle $3.3^{\circ}$ and penetration depth $0.19 \mathrm{~mm}$. These parameters were established by response surface methodology by conducting 31 experiments based on a design of experiments in the selected range.

Bending Test specimens of rectangular cross-section were cut from the fabricated composite. The specimen rests on two supports and is loaded by means of a loading nose at mid distance between the supports.

\subsection{Hot Deformation in Uni-axial Tension}

Hot tensile tests were conducted to determine the optimal forming temperature. Specimens, prepared as per ASTM E2448 standards, were used (see Figure 1).

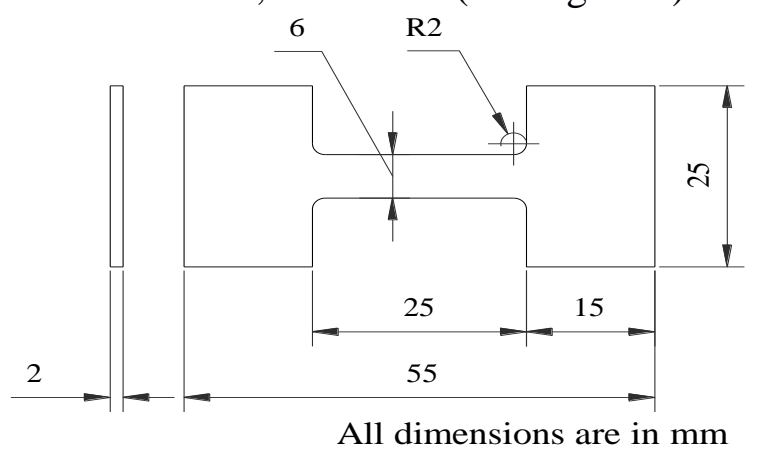

Figure 1 Dimensions of hot tensile test Specimen 
A tubular furnace fitted with a micro-controller was used for heating and maintaining the selected specimen temperature. A constant cross-head velocity of $1.5 \mathrm{~mm} \cdot \mathrm{min}^{-1}$ was maintained in all the tests. Tests were conducted at four temperatures, viz. $573 \mathrm{~K}, 623 \mathrm{~K}, 673 \mathrm{~K}$ and $723 \mathrm{~K}$. The gripper used for gripping the specimens was designed as per ASTM E2448 standard. The temperature at which the percentage elongation was the highest was selected as the forming temperature while attempting to produce a hemispherical component.

\section{$2.4 \quad$ Free Blow Forming}

\subsubsection{Experimental Setup}

Blow forming was conducted using a four column 100 tonne deep drawing hydraulic press (Make: India) with a Yuken make power pack, daylight gap of $1100 \mathrm{~mm}$, centre height of $600 \mathrm{~mm}$, stroke length of $800 \mathrm{~mm}$ and power of $15 \mathrm{HP}$ with (Crompton Greaves) motor to hold the blanks. The setup consists of top and bottom dies held within the hydraulic press. The top and bottom dies were enclosed by a circular band heater of capacity $1500 \mathrm{~W} \times 220 \mathrm{~V}$ to heat the specimens to the selected temperature. A pressure control valve was used to maintain constant pressure during forming. A precision dial gauge inserted into the vent hole of the bottom die was used to measure the pole height at a time interval of 5 seconds. Characteristics such as the forming time required by the component to reach a specified pole height were measured using a stopwatch and other necessary accessories.

\subsubsection{Specimen Preparation}

Sheet forming experiments were performed using AA6061/SiC $\mathrm{p}_{\mathrm{p}}$ composite produced by FSP, as described above. The thickness of the work-piece was $6 \mathrm{~mm}$, whereas the required thickness for sheet forming is $1.5 \mathrm{~mm}$. Therefore, the composite specimens were machined using a CNC milling machine to reduce the thickness to $1.5 \mathrm{~mm}$, and later cut to a diameter of $73 \mathrm{~mm}$ using a wire-cut EDM machine (Make: SODICK AQ 427L). In this condition the sheet is suitable for blow forming at elevated temperatures.

\subsubsection{Die Design}

Matching halves (top and bottom) of the die needed for forming were made out of AISI 304 grade stainless steel. The bottom die has the required die cavity and a groove for seating the specimen. It contains a vent hole for inserting the displacement measuring device and also for venting out the air inside the cavity being expelled during forming. The top die is provided with an inlet for argon gas and a projection suitable to achieve a perfect fit with the bottom die. This prevents leakage of the gas to the atmosphere during forming. An aspect ratio of 0.5 (height to diameter ratio) was used for designing the die cavity (a hemispherical shape). The dimensions of the top and bottom dies are shown in Figures 2 and 3 respectively.

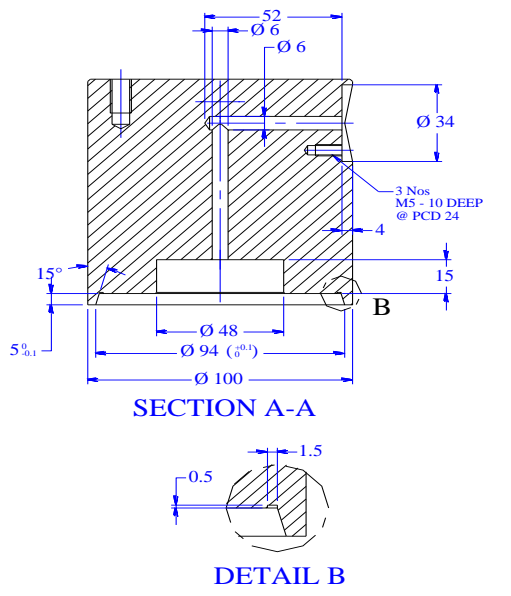

All dimensions are in millimeters

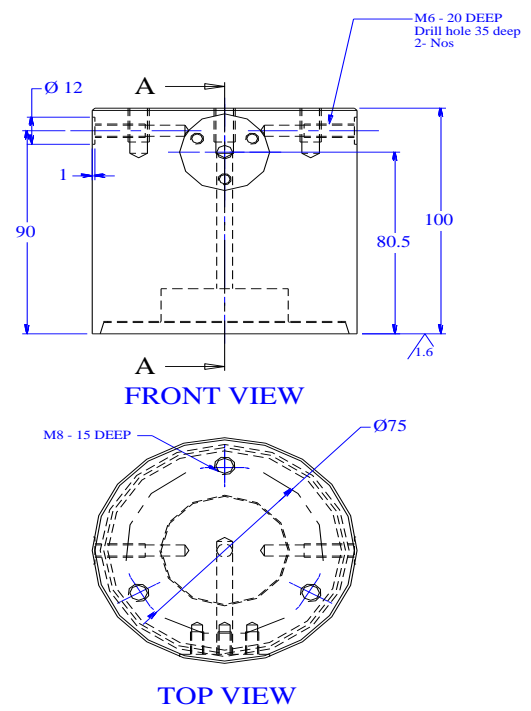

Figure 2 Elevation and Plan views of the top die 

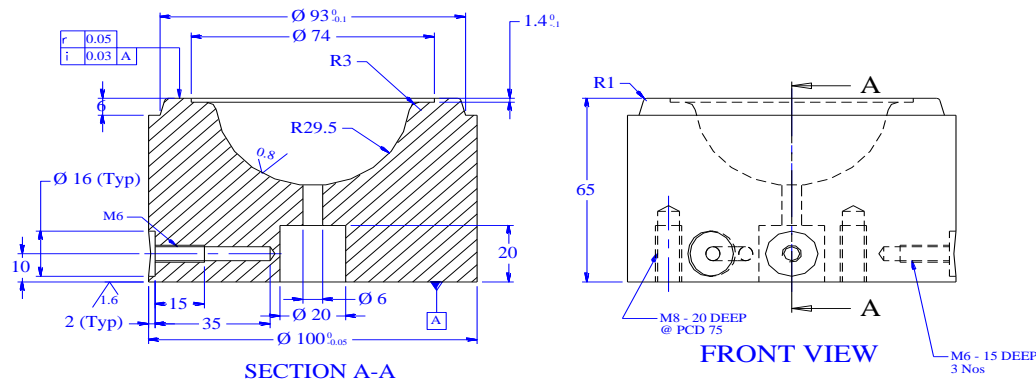

All dimensions are in millimeters

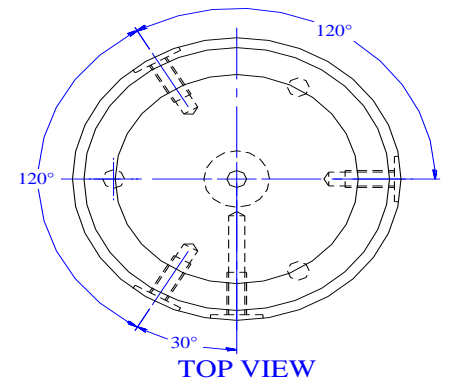

Figure 3 Elevation and Plan views of the bottom die

The die opening radius was $31.5 \mathrm{~mm}$, while the corner radius was machined to $3 \mathrm{~mm}$. The entire die assembly was set in a hydraulic press to provide both proper alignments between the two dies and also prevent leakage of argon gas during forming. The assembled view of the die setup is shown in Figure 4.

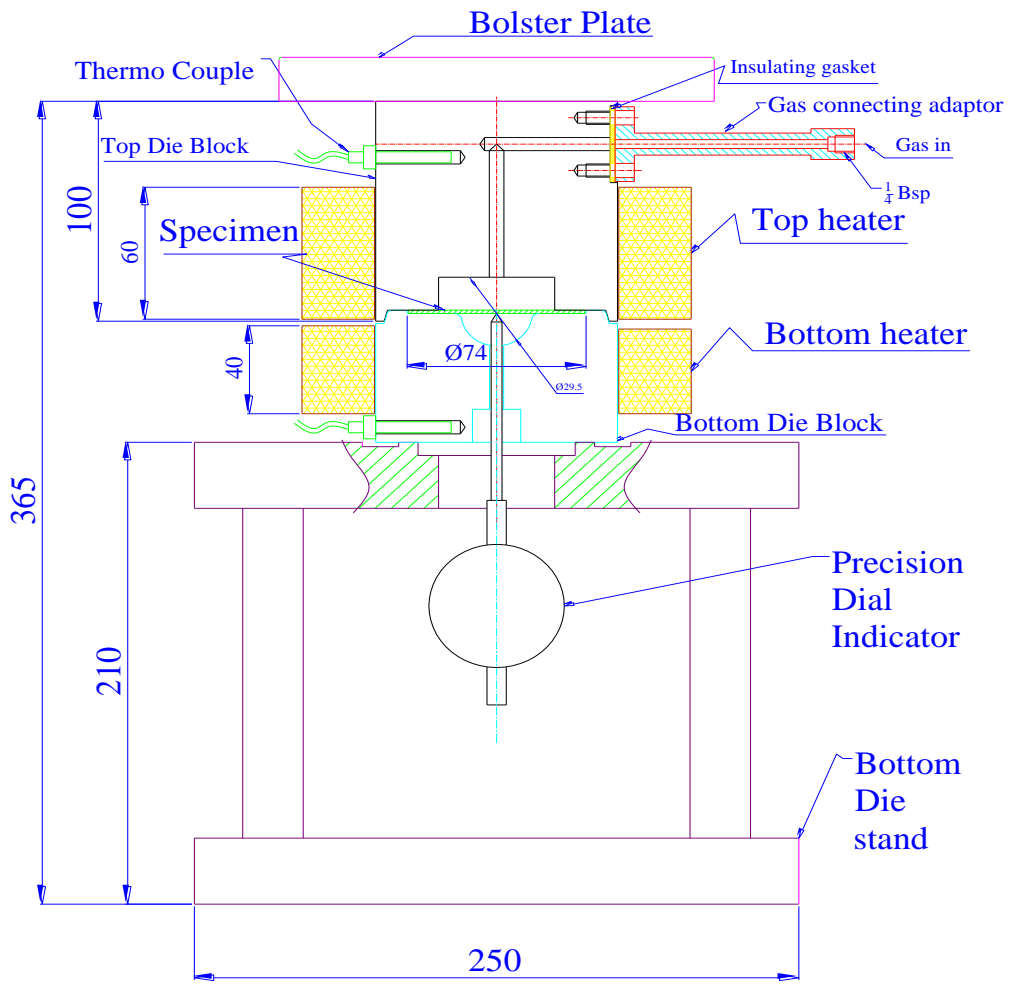

All dimensions are in millimeters

Figure 4 Assembled view of the die set-up

\section{RESULTS AND DISCUSSION}

3.1 Three Point Bend Test 
The average grain size in the as-received material was $140 \mu \mathrm{m}$, while that of FSP material, without $\mathrm{SiC}_{\mathrm{p}}$ reinforcements, was $20 \mu \mathrm{m}$. The alloy containing $\mathrm{SiC}_{\mathrm{p}}$ particles, after FSP, had a grain size $30 \mu$. The results (pertaining to the starting specimen and after the tests) from the room temperature bend tests are shown in Figure 5. The plates were bent at an angle of $30^{\circ}$. In all the cases the FSP zone was on the top layers of the plates, where the plane strain was the greatest. It is subjected to both bending and tension due to which cavity formation and cracking could develop. An increase in formability is reflected as an increase in the critical plane strain value and it is known that this (increased formability) is facilitated by a decrease in grain size. As only to be expected, the FSP treated plates of the as-received material, without $\mathrm{SiC}_{\mathrm{p}}$ particles was much more ductile, but had a much lower yield strength compared with the $\mathrm{SiC}_{\mathrm{p}}$-added specimen. That the surface modification in the composite led to a clear loss of ductility in the sample is evident from the failure seen in Figure 5b.
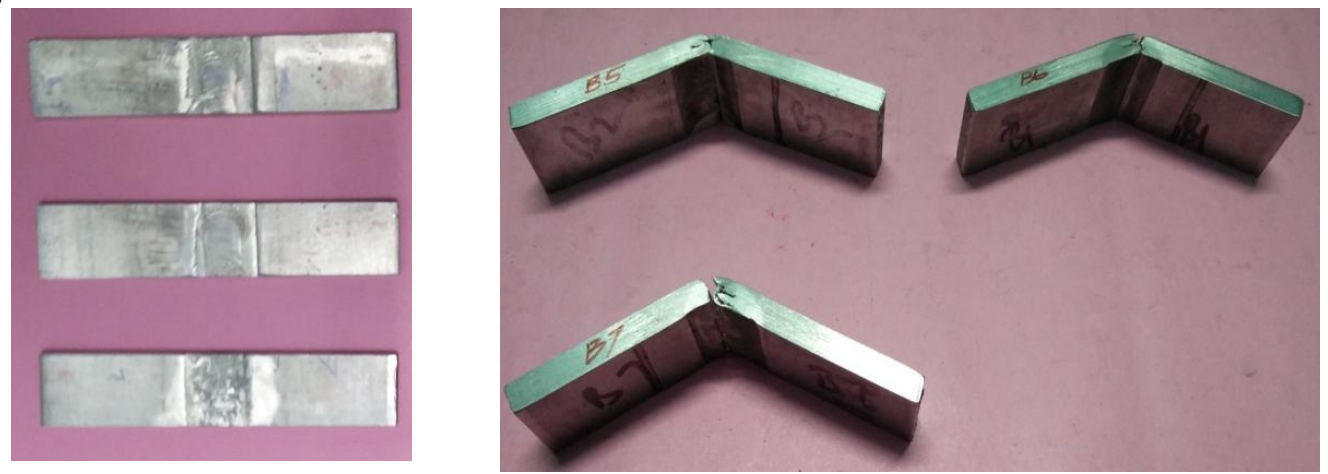

Figure 5 (a-b) Three point bending test specimens before and after test

The quantitative difference in the strength of the FSP-treated material, with and without $\mathrm{SiC}_{\mathrm{p}}$ particles, is given in Table 1 . As $\mathrm{SiC}_{\mathrm{p}}$ reinforcement improves the strength of the Al-alloy, while at the same time it decreases the grain size, it is interesting to check if superplasticity / extended plasticity is present in this alloy in this treated condition.

Table 1 Bending strength values of different specimens

\section{2}

\begin{tabular}{|l|c|}
\hline \multicolumn{1}{|c|}{ Specimen Condition } & Bending Load in KN \\
\hline FSP treated plate without particles & 1.53 \\
\hline FSP treated plate with particles - Trial 1 & 2.04 \\
\hline FSP treated plate with particles - Trial 2 & 2.13 \\
\hline
\end{tabular}

Uniaxial elevated temperature tests on composite sheets fabricated through FSP were conducted to identify the optimal forming temperature and strain rate for bi-axial stressing. Figure 6 presents the elongated FSP-composite specimens at various temperatures. As is only to be expected, the flow stress decreased with increasing temperature. However, when the temperature was above a certain value, significant grain coarsening led to higher flow stresses and lower elongations. This is in conformity with what is reported in the literature concerning creep (Padmanabhan \& Davies 1980).

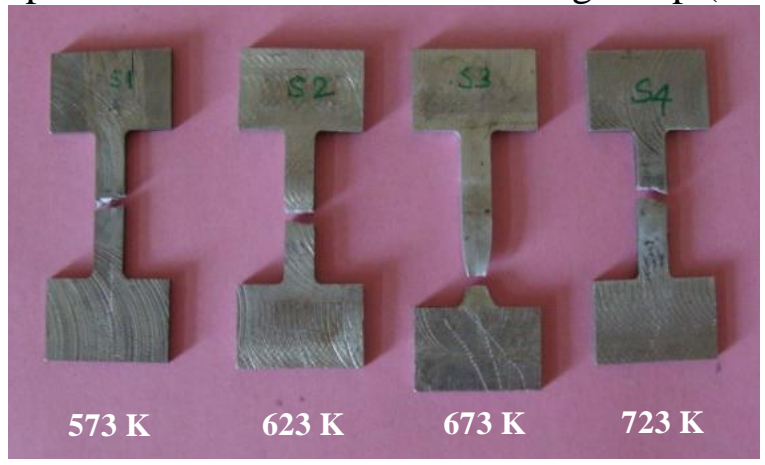

Figure 6 Hot tensile tested specimens $\left(\mathrm{AA6061/ \textrm {SiC } _ { \mathrm { p } } )}\right.$ ) at different temperatures 
Due to the presence of hard and brittle $\mathrm{SiC}_{\mathrm{p}}$ reinforcements, the percentage elongations obtained in the specimens were much less than what is usually seen in highly ductile alloys. The maximum elongations obtained in each of the test temperatures are given in Table 2.

Table 2 Percentage elongation of the fabricated composites at elevated temperatures

\begin{tabular}{|c|c|c|}
\hline $\begin{array}{c}\text { Sl. } \\
\text { No. }\end{array}$ & Temperature & $\begin{array}{c}\text { \% of elongation } \\
\mathbf{A A 6 0 6 1}_{\mathbf{S i C}} \mathbf{p}\end{array}$ \\
\hline 1 & $573 \mathrm{~K}$ & 14 \\
\hline 2 & $623 \mathrm{~K}$ & 21 \\
\hline 3 & $673 \mathrm{~K}$ & 26 \\
\hline 4 & $723 \mathrm{~K}$ & 19 \\
\hline
\end{tabular}

\subsection{BLOW FORMING INTO A HEMISPHERICAL DIE CAVITY}

For blow forming the Al-SiC $\mathrm{p}_{\mathrm{p}}$ composite sheets (only FSP-treated composite specimens were used in these experiments) into a hemispherical die cavity, where the sheet will experience biaxial stressing, $623 \mathrm{~K}$ and $673 \mathrm{~K}$ were selected as the test temperatures due to the higher tensile elongations obtained (See Table 2). The forming pressures were 0.2 MPa and 0.25 MPa. At both the pressures the sheets could not reach a radius $29.5 \mathrm{~mm}$ needed to form a hemisphere. The maximum bulge height achieved was $18 \mathrm{~mm}$ for the $\mathrm{AA} 6061 / \mathrm{SiC}_{\mathrm{p}}$ composite at a forming pressure of $0.2 \mathrm{MPa}$. When the argon gas pressure was raised to $0.3 \mathrm{MPa}$, the composite ruptured within $10 \mathrm{~s}$, without any significant bulge height development. Similarly for forming pressures below $0.2 \mathrm{MPa}$ the sheets did not exhibit any bulging. Hence, the forming pressure was set as either $0.2 \mathrm{MPa}$ or $0.25 \mathrm{MPa}$ in the present experiments.

\subsubsection{Bulge Height Vs Forming Time}

Figures 7, 8 display the variation in the bulge height with the forming time for the specimens formed at different pressures and a specified temperature. As only to be expected, with increasing forming pressure (which leads to increased strain rate of deformation) the forming time decreases.

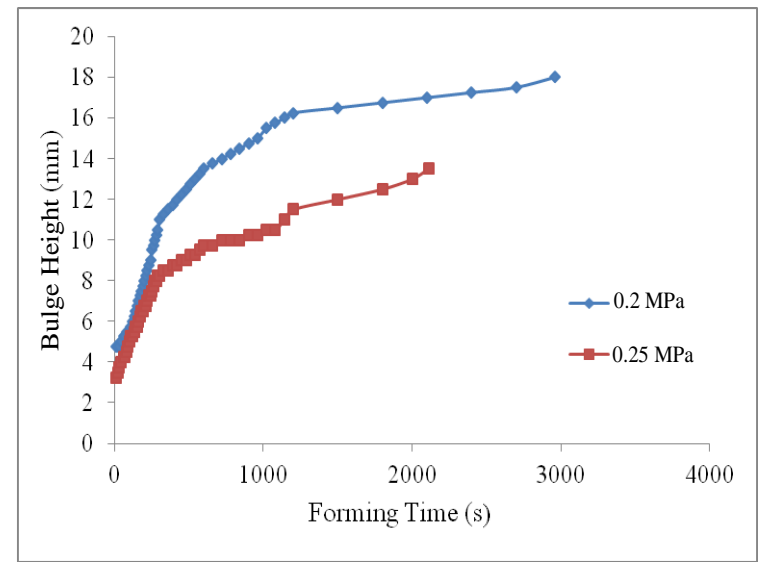

Figure 7 Bulge height versus forming time at $623 \mathrm{~K}$ for $\mathrm{SiC}_{\mathrm{p}}$ composite

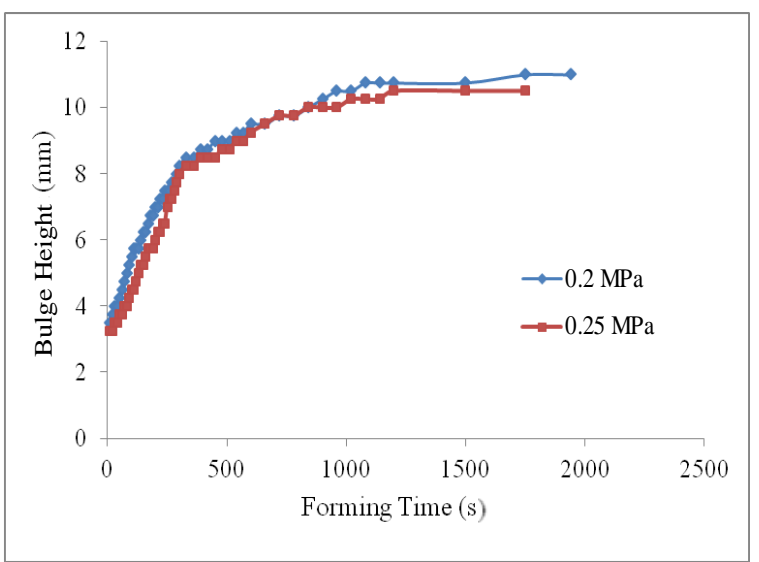

Figure 8 Bulge height versus forming time at $673 \mathrm{~K}$ for $\mathrm{SiC}_{\mathrm{p}}$ composite

The variation of bulge height with respect to forming time at two different temperatures and a fixed forming pressure is shown in Figures 9, 10. The forming time and the flow stress decrease with increasing temperature. In all cases, it was observed that the initial part of the plot was characterized by an abrupt increase in the bulge height. The strain rate was around $1.5 \times 10^{-3} \mathrm{~s}^{-1}$. In the later part of the bulge height - time of deformation curve, the slope was almost constant, which indicates the presence of a steady state of flow. In this region the strain rate was $\sim 1 \times 10^{-3} \mathrm{~s}^{-1}$.

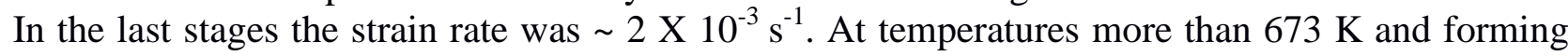


pressures greater than $0.25 \mathrm{MPa}$, the strain rate was too high, the value of the strain rate sesitivity index was lower and a fracture of the sheet was observed.

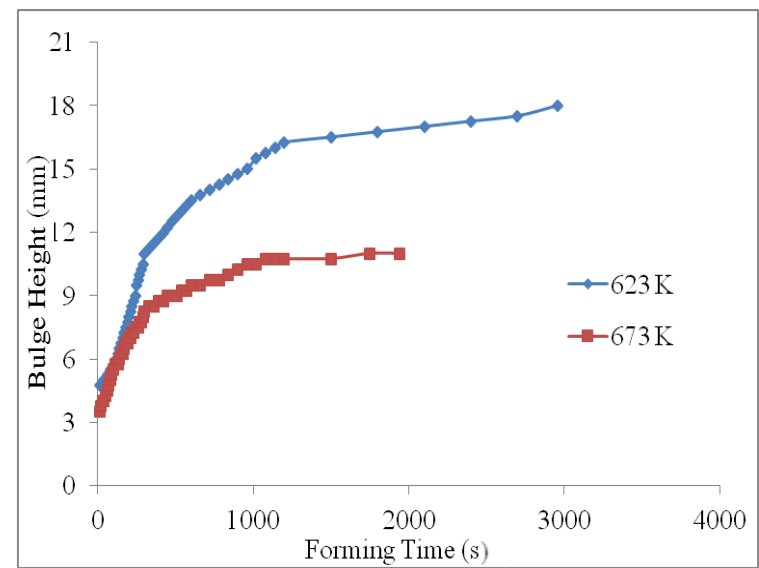

Figure 9 Bulge height versus forming time at $0.2 \mathrm{MPa}$ for $\mathrm{SiC}_{\mathrm{p}}$ composite

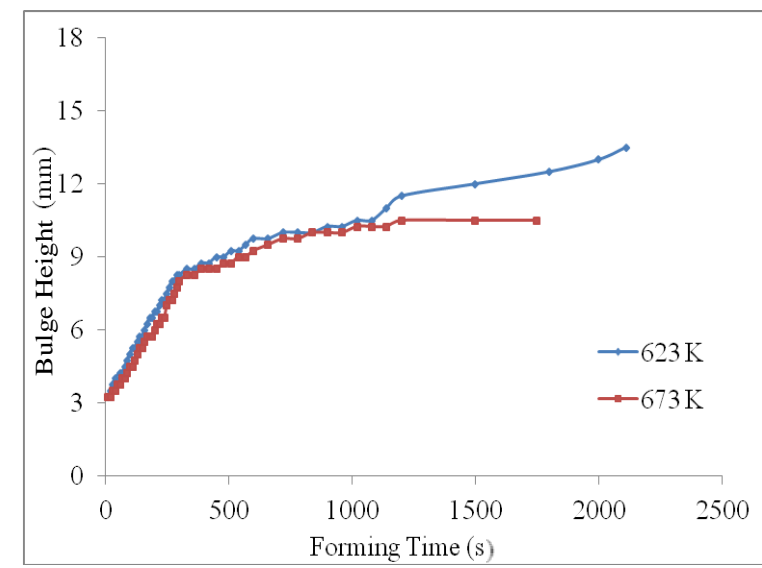

Figure 10 Bulge height versus forming time at $0.25 \mathrm{MPa}$ for $\mathrm{SiC}_{\mathrm{p}}$ composite

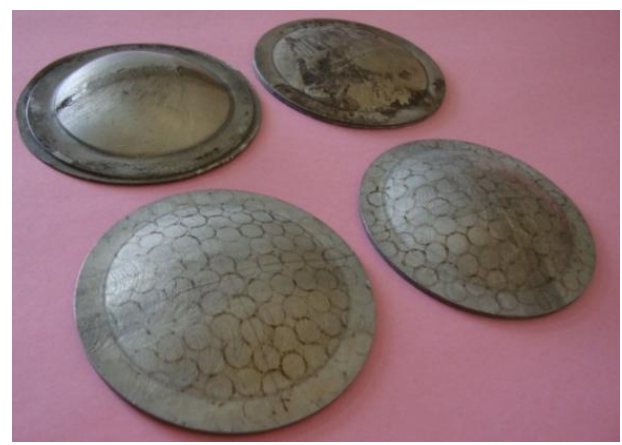

Figure 11 Sheets of the composite subjected to bi-axial stressing

The blow formed composites at two different forming temperatures and pressures are shown in Figure 11. The experimental forming time and peak formed height for the AA6061/ $\mathrm{SiC}_{\mathrm{p}}$ composite sheets are shown in Table 3.

Table 3 Forming time of the $\mathrm{AA6061} / \mathrm{SiC}_{\mathrm{p}}$ composite into a hemispherical die

\begin{tabular}{|c|c|c|c|c|}
\hline $\begin{array}{c}\text { Sl. } \\
\text { No. }\end{array}$ & $\begin{array}{c}\text { Forming temperature } \\
(\mathbf{K})\end{array}$ & $\begin{array}{c}\text { Forming Pressure } \\
\mathbf{( M P a}\end{array}$ & $\begin{array}{c}\text { Peak height attained } \\
(\mathbf{m m})\end{array}$ & $\begin{array}{c}\text { Forming } \\
\text { time (s) }\end{array}$ \\
\hline \multirow{2}{*}{1} & \multirow{2}{*}{$623 \mathrm{~K}$} & 0.2 & 18 & 2960 \\
\cline { 2 - 5 } & \multirow{2}{*}{2} & 0.25 & 13.5 & 2110 \\
\cline { 2 - 5 } & $673 \mathrm{~K}$ & 0.2 & 11 & 1940 \\
\hline
\end{tabular}

\subsubsection{Effect of the FSP on Bulge Forming}

Although only the centre of the specimen (in the sheet plane) was subjected to FSP, during blow forming, material from both the FSP and non-FSP zones deformed. The grain size is much finer in the FSP zone (caused by severe plastic deformation). A blow formed specimen is shown in Figure 12. It is seen that rupture has taken place in the FSP zone, an indication of the lower potential plasticity of the zone containing the reinforcements compared with the region of just the matrix alloy. The differences in the grain sizes of the FSP zone and the untreated region as also the FSP zone containing the $\mathrm{SiC}_{\mathrm{p}}$ particles, with their inherent significant differences in the flow stresses, could also have contributed to the observed steep strain gradients and failures at the locations in which they are present. 


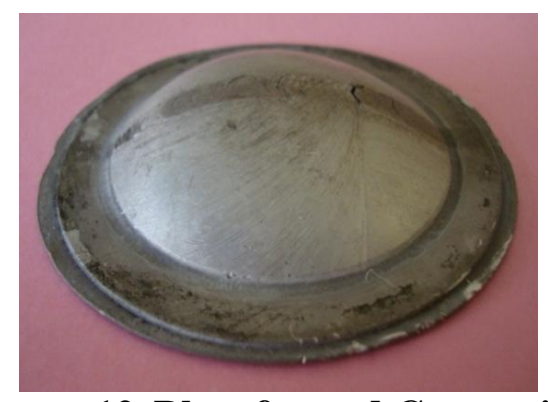

Figure 12 Blow formed Composite

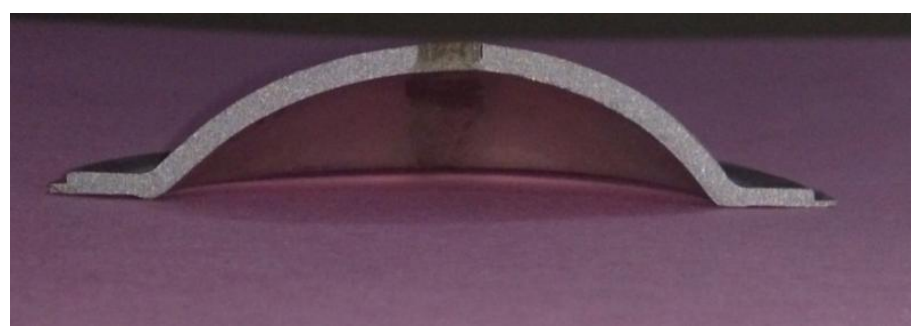

Figure 13 Thickness distribution as a function of bulge height

Figure 13 shows the thinning behaviour of the composite sheet. It is observed that the thickness along the profile is almost uniform, with more thinning in the thermo mechanically affected zone region compared with the stirred region.

\subsubsection{Determination of the Material Parameters}

The stress - strain curves for the composite specimens are shown in Figures 14, 15 respectively. The flow stress, instantaneous thickness and true strain have been calculated using the following equations (Jung-Ho Cheng 1996).

$$
\text { Flow stress }(\sigma)=\frac{p\left(R^{2}+h^{2}\right)^{2}}{4 h R^{2} s_{0}} \quad-1
$$

Where ' $p$ ' is the blow forming pressure, ' $R$ ' is the radius of the die opening, ' $h$ ' is the bulge height, ' $\mathrm{s}_{0}$ ' is the initial thickness of the specimen.

$$
\begin{aligned}
& \text { Instantaneous thickness }(s)=\frac{R^{2} s_{0}}{R^{2}+h^{2}} \quad-\quad 2 \\
& \text { True strain }(\varepsilon)=\ln \frac{s}{s_{0}} \quad-3
\end{aligned}
$$

At a given temperature an increase in gas pressure gets translated as an increase in the true stress (Ramesh Babu et al. 2014). Beyond a certain pressure, the component ruptures very early because the strain rates are too high to allow significant plasticity in the material. In the present case, it could be established experimentally that at $623 \mathrm{~K}$ and $673 \mathrm{~K}$ the maximum permissible argon gas pressure was $0.25 \mathrm{MPa}$ for reasonably good degree of forming.

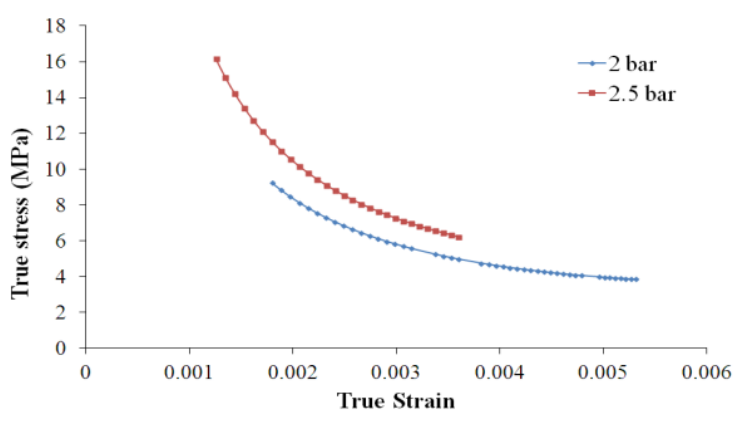

Figure 14 True Stress-strain curves at $623 \mathrm{~K}$ for $\mathrm{SiC}_{\mathrm{p}}$ composite in constant gas pressure bi-axial stressing

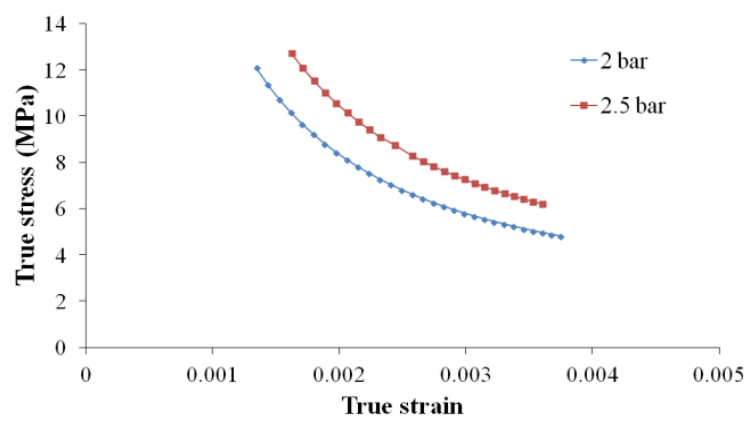

Figure 15 True Stress-strain curves at $673 \mathrm{~K}$ for $\mathrm{SiC}_{\mathrm{p}}$ composite in constant gas pressure bi-axial stressing 
When the gas pressure applied is constant in a test, with increasing time of forming, the stress decreases due to an increase in the surface area of the formed dome. To maintain forming at the same strain rate, therefore, the gas pressure has to be increased. This was not tried here. Figures 16, 17 display the variation of flow stress and strain rate sensitivity index, $\mathrm{m}$, with strain rate in the composite specimens fabricated by FSP and subjected to bi-axial stressing. " $\mathrm{m}$ " is determined by establishing a relationship between the flow stress and the strain rate for a particular pressure and temperature.

It is known that the stress and strain rate are calculated from the applied gas pressure and the increase in the area of the dome being formed (Equations 1 and 3) and the strain rate sensitivity index $(\mathrm{m})$ is determined using Equation 4 as given below. Then, the variation of $\mathrm{m}$ with strain rate can be easily plotted.

$$
m=\ln ^{\ln \frac{\sigma_{2}}{\sigma_{1}}} / \ln \frac{\varepsilon_{2}}{\varepsilon_{1}} \quad-4
$$

where ' $\sigma$ ' is the stress applied in MPa and ' $\varepsilon$ ' is the strain rate in $\mathrm{s}^{-1}$. The subscripts ' 1 ' and ' 2 ' in the numerator stand for the first and second stress levels. Similarly, the subscripts ' 1 ' and ' 2 ' in the denominator stand for the first and second strain rate levels for the corresponding stresses.

(a)

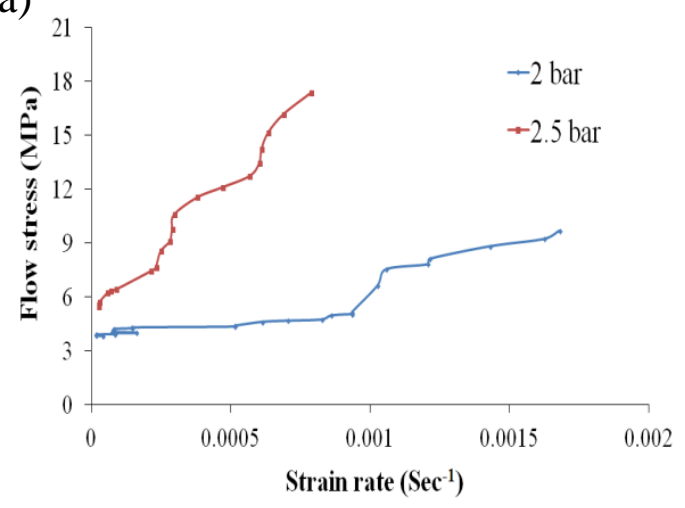

(b)

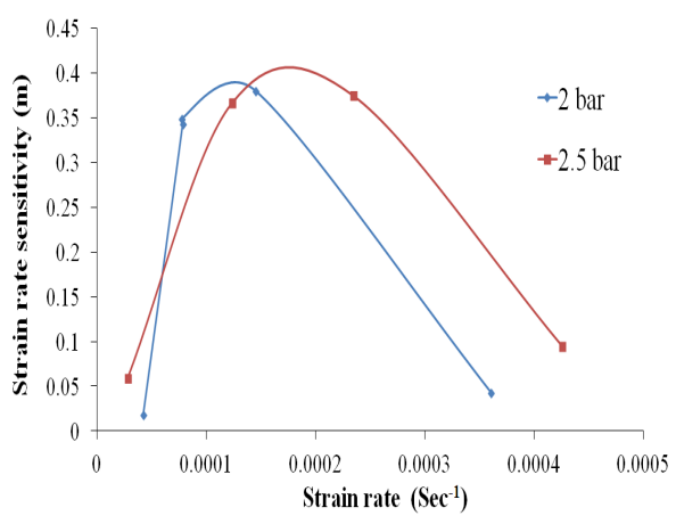

Figure 16(a) Flow Stress-strain rate, (b) Strain rate sensitivity index-strain rate curves at $623 \mathrm{~K}$ for $\mathrm{SiC}_{\mathrm{p}}$ composite
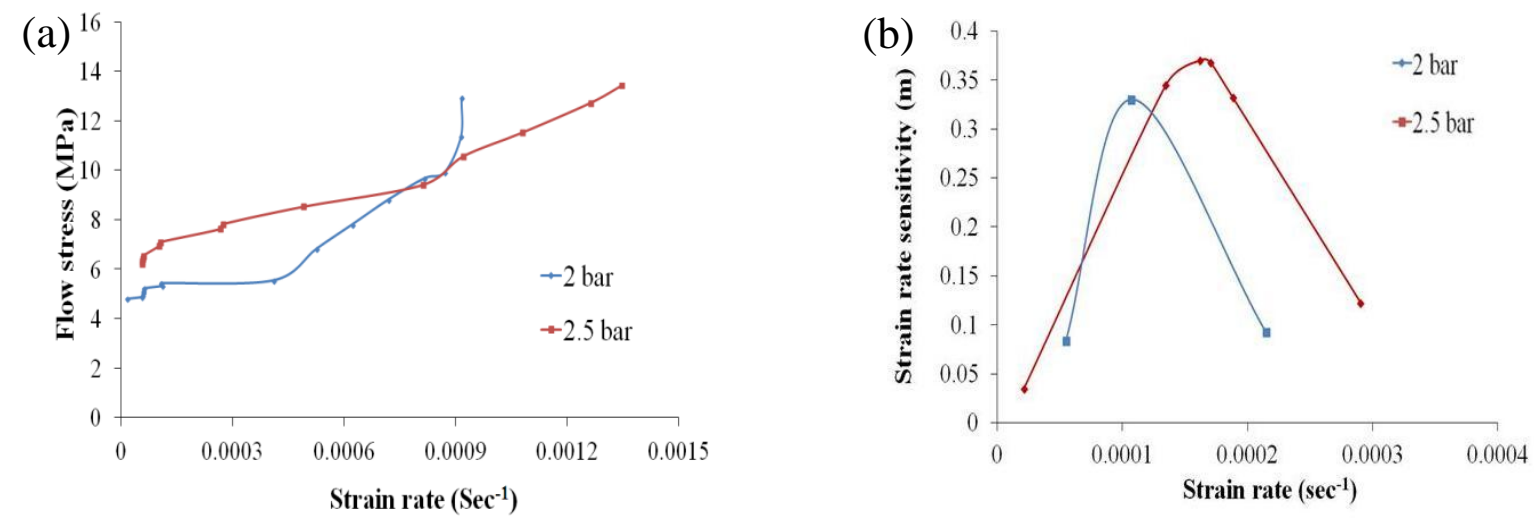

Figure 17(a) Flow Stress-strain rate, (b) Strain rate sensitivity index-strain rate curves at $673 \mathrm{~K}$ for $\mathrm{SiC}_{\mathrm{p}}$ composite 
It is observed that with increasing forming gas pressure, the flow stress and strain rate sensitivity index of the composite shifts towards the right. That is, in the present experimental range, with increasing strain rate, the flow stress and the strain rate sensitivity index values increase. The values of ' $\mathrm{m}$ ' at various temperatures were determined and they are given in Table 4. From the values, it is found that at a constant temperature, within the experimental range, as the pressure increases, the strain rate sensitivity index increases.

Table 4 Strain rate sensitivity index of the fabricated composites

\begin{tabular}{|c|c|c|c|}
\hline $\begin{array}{c}\text { Sl. } \\
\text { No. }\end{array}$ & $\begin{array}{c}\text { Forming temperature } \\
(\mathbf{K})\end{array}$ & $\begin{array}{c}\text { Forming Pressure } \\
(\mathbf{M P a})\end{array}$ & $\begin{array}{c}\text { AA6061/SiC } \\
\text { value of ' } \mathbf{~ m} \text { ” }\end{array}$ \\
\hline \multirow{2}{*}{1} & \multirow{2}{*}{$623 \mathrm{~K}$} & 0.2 & 0.38 \\
\cline { 2 - 4 } & \multirow{2}{*}{2} & 0.25 & 0.40 \\
\cline { 2 - 4 } & \multirow{2}{*}{$673 \mathrm{~K}$} & 0.2 & 0.33 \\
\hline
\end{tabular}

A value of $\mathrm{m} \sim 0.4$ should lead to superplastic behavior. Yet, it was not seen in the present study, mainly due to the steep strain and stress gradients developed in the composite material. A finer and more homogeneous distribution of the $\mathrm{SiC}_{\mathrm{p}}$ particles in the Al6061 matrix could give rise to superplasticity in the composite. This will be the subject of a future investigation. We have also performed forming experiments with plain AA6061 alloy and friction stir processed AA6061 (without the addition of the $\mathrm{SiC}_{\mathrm{p}}$ particles). Discussion on their relative performance is not presented here due to a limitation on space.

\section{CONCLUSIONS}

AA $6061 / \mathrm{SiC}_{\mathrm{p}}$ composite was processed using FSP. Subsequently, formability characteristics/ properties were identified. Three point bend tests were conducted to identify the changes in the formability. Uniaxial tensile tests were conducted on the composite sheets fabricated through FSP to identify the optimal forming temperatures. Subsequently, the composite sheets were subjected to bi-axial stressing at the selected temperatures of $623 \mathrm{~K}$ and $673 \mathrm{~K}$ for determining the range of forming pressures in which the formation of hemisphere-shaped components should be attempted.

- A maximum bulge height of $18 \mathrm{~mm}$ was achieved for $\mathrm{AA6061/SiC_{p }}$ composite at a forming gas pressure of $0.2 \mathrm{MPa}$ at $623 \mathrm{~K}$. A full hemispherical shape could not be achieved in the present experiments.

- Within the present experimental range, the strain rate sensitivity index value of the composite lies in the range of 0.33 to 0.40 for various combinations of forming pressure and temperature. This suggests that through better microstructure control it should be possible to induce superplasticity in this material (as $\mathrm{m}>=0.3$ is a characteristic of the superplastic region)

- Strain rate sensitivity index increases with increasing forming pressure from 0.2 to $0.25 \mathrm{MPa}$.

- These findings can pave the way for the commercial exploitation of the FSP-technology-based fabrication of $\mathrm{AA} 6061 / \mathrm{SiC}_{\mathrm{p}}$ composite in view of its considerable scope for improved formability.

\section{ACKNOWLEDGEMENTS}

The authors express their gratefulness to the Science \& Engineering Research Board, Department of Science and Technology (SERB-DST), New Delhi, India, for their financial assistance for conducting the research work through project no. SR/S3/MERC/0092/2011.

\section{REFERENCES}

1. Barnes, AJ, Superplastic forming 40 years and still growing, Journal of Material Performance and Engineering (2007), vol.16, pp. 440-454. 


\section{$11^{\text {th }}$ EUROSPF Conference}

2. Cavaliere, $\mathrm{P} \&$ Squillace, A, High temperature deformation of friction stir processed 7075 aluminium alloy, Materials Characterization (2005), vol. 55, pp. 136- 142.

3. Charit, I \& Mishra, RS, High strain rate superplasticity in a commercial 2024 Al alloy via friction stir processing, Materials and Engineering A (2003), vol. 359, pp. 290-296.

4. Giuliano, G, Superplastic forming of advanced metallic materials, First Edition, Woodhead Publishing Limited (2011), Cambridge, UK.

5. Giuliano, G, Constitutive modelling of superplastic AA-5083, Technische Mechanik (2012), vol. 32, pp.221-226.

6. Jung-Ho Cheng, The determination of material parameters from superplastic inflation tests, Journal of Material Processing Technology (1996), vol. 58, pp. 233-246.

7. Kannan, K, Johnson, $\mathrm{CH} \&$ Hamilton $\mathrm{CH}$, A study of superplasticity in a modified $5083 \mathrm{Al}-\mathrm{Mg}$-Mn alloy, Metallurgical and materials Transactions A (1998), vol. 29 A, pp. 1211-1220.

8. Karthikeyan, L, Senthil Kumar, VS \& Padmanabhan, KA, Biaxial Stressing of Sheets of Friction Stir Processed Aluminum Alloy A319, Materials and Manufacturing Processes (2010), vol. 25, pp.12971303.

9. Karthikeyan, L, Senthil Kumar, VS \& Padmanabhan, KA, Investigations on superplastic forming of friction stir-processed AA6063-T6 aluminium alloy, Materials and Manufacturing processes (2013), vol. 28, pp. 294-298.

10. Ma, ZY, Mishra, R \& Mahoney, M, Superplasticity in cast A356 induced via friction stir processing, Scripta Materialia (2004), vol. 50, pp.931-935.

11. Mahoney, MW \& Lynch, SP, Friction Stir Processing, Rockwell Scientific Co. LLC, Ca91360, USA, DARPA communication(2000).

12. Padmanabhan, KA \& Davies, Superplasticity, Material Research and Engineering 2, Springer Verlog Berlin Heidelberg (1980), New York.

13. Ramesh Babu, S, Senthil Kumar, VS, Karunamoorthy, L \& Madhusudhan Reddy, G, Investigation on the effect of friction stir processing on the superplastic forming of AZ31B alloy, Materials and Design (2014), vol.53, pp.338-348.

14. Senthil Kumar, VS, Viswanathan, D \& Natarajan, S, Theoretical prediction and FEM analysis of superplastic forming of AA 7475 aluminium alloy in a hemispherical die, Journal of Materials Processing Technology (2006), vol. 173, pp. 247-251. 